\title{
A UPLC-MS/MS METHOD DEVELOPMENT AND VALIDATION FOR THE ESTIMATION OF SOFOSBUVIR FROM HUMAN PLASMA
}

\author{
DARSHAN BHATTa ${ }^{*}$ B. RAJKAMAL \\ aMewar University, Gangrar, Chittorgarh 312901, Rajasthan, India, bKVK College of Pharmacy, Surmajiguda, Hyderabad 501512, \\ Telangana, India \\ Email: darshanbhatt1984@gmail.com \\ Received: 13 Oct 2016, Revised and Accepted: 05 Dec 2016
}

\begin{abstract}
Objective: The present work aimed to develop a simple, rapid, specific and precise ultra-performance liquid chromatography-tandem mass spectrophotometric (LC-MS/MS) validated method for quantification of sofosbuvir and internal standard (ISTD) Sofosbuvir-d3 in human plasma.

Methods: Samples prepared by employing liquid-liquid extraction (LLE) using $2.5 \mathrm{ml}$ of ethyl acetate. Chromatographic separation was achieved on Gemini $5 \mu$ C18, 50 x $4.6 \mathrm{~mm}$ column using a mixture of $0.1 \%(\mathrm{v} / \mathrm{v}$ ) formic acid in water to methanol at a ratio of $30: 70 \mathrm{v} / \mathrm{v}$ as the mobile phase. The flow rate was $0.50 \mathrm{ml} / \mathrm{min}$. The LC eluent was split, and approximately $0.1 \mathrm{ml} / \mathrm{min}$ was introduced into Tandem mass spectrometer using turbo Ion Spray interface at $325^{\circ} \mathrm{C}$. Quantitation was performed by transitions of 428.35/279.26 (m/z) for sofosbuvir and 431.38/282.37 ( $\mathrm{m} / \mathrm{z}$ ) for sofosbuvir-d3.

Results: The concentrations of ten working standards showed linearity between 4.063 to $8000.010 \mathrm{ng} / \mathrm{ml}\left(r^{2} \geq 0.9985\right)$. Chromatographic separation was achieved within $2 \mathrm{~min}$. The average extraction recoveries of three quality control concentrations were $75.36 \%$ for sofosbuvir and were within the acceptance limits. The coefficient of variation was $\leq 15 \%$ for intra-and inter-batch assays. The $\%$ CV of ruggedness ranges $0.35 \%$ and $3.09 \%$. The $\%$ stability of short term and long term stock solution stability studies was found to be $97.25 \%$ and $98.81 \%$ respectively.
\end{abstract}

Conclusion: The results obtained for specificity, linearity, accuracy, precision, ruggedness and stability studies were within the acceptance limits. Thus the validated economical method was applied for pharmacokinetic studies of sofosbuvir.

Keywords: Sofosbuvir, LC-MS/MS, Human plasma, Stability studies

(C) 2016 The Authors. Published by Innovare Academic Sciences Pvt Ltd. This is an open access article under the CC BY license (http://creativecommons.org/licenses/by/4.0/) DOI: http://dx.doi.org/10.22159/ijap.2017v9i1.15652

\section{INTRODUCTION}

Sofosbuvir, a phosphoramidate prodrug, is chemically described as $(S)$-Isopropyl 2-((S) $((2 R, 3 R, 4 R, 5 R)-5$-(2, 4-dioxo-3,4-dihydropyrimidin-1(2H)-yl)-4-fluoro-3-hydroxy-4 methyl tetrahydrofuran2-yl) methoxy)-(phenoxy) phosphorylamino) propanoate [1-2]. Literature survey reveals two HPLC methods for determination of sofosbuvir from its bulk and pharmaceutical dosage forms [3-4]. Three UPLC-MS/MS method were reported for quantification of sofosbuvir from its metabolites and along with other drugs from human plasma [5-7]. Described here is a simple, sensitive, and selective UPLC-MS/MS method for sofosbuvir in the human plasma concentration range of 4.063 to $8000.010 \mathrm{ng} / \mathrm{ml}$. As there is no literature on stability and validation details of sofosbuvir estimation from human plasma, this study performed assay validations, according to the FDA guidelines [8]. While this method with validation details were economical and applied for pharmacokinetic studies of sofosbuvir.

\section{MATERIALS AND METHODS [5]}

\section{Apparatus and software}

The UPLC (Waters, Model Acquity) was coupled with Mass spectrometer (Waters Quattro Premier XE) having Turbo Ion Spray (Waters Quattro Premier XE). The chromatographic integration was performed by MassL ynx V4.1 software.

\section{Chemicals and reagents}

Sofosbuvir and Sofosbuvir-d3 (IS) were procured from Mylan Laboratories Ltd, Hyderabad, Formic acid, Methanol and ethyl acetate was procured from Merck Specialities Pvt. Ltd, Mumbai, India. Water used was collected from water purification systems (Milli Q, MilliPore, USA) installed in the laboratory. Pooled drug-free expired frozen human plasma (K2-EDTA as anticoagulant) was obtained froma Blood Bank, Hyderabad, was used during validation and study sample analysis. The plasma was stored into- $70 \pm 5^{\circ} \mathrm{C}$.

\section{Standards and working solutions}

\section{Calibration standard solutions}

Stock solutions of sofosbuvir and Sofosbuvir-d3 internal standard (IS) were prepared in methanol. Further dilutions were carried out in $50 \%$ methanol. Calibration standards often concentration levels were prepared freshly by spiking drug-free plasma with a sofosbuvir stock solution to give the concentrations of $4.063,8.125,62.5,125.0$, $250,500,1000,2000,4000$ and $8000 \mathrm{ng} / \mathrm{ml}$.

\section{Quality control standards}

Lowest quality control standards, Median quality control standards and highest quality control standards were prepared by spiking drug-free plasma with sofosbuvir to give a solution containing $11.488,522.180$ and $7252.503 \mathrm{ng} / \mathrm{ml}$ respectively. They were stored at- $20{ }^{\circ} \mathrm{C}$ till the time analysed.

\section{Chromatographic conditions}

Chromatographic separation was performed on Gemini $5 \mu$ C18, 50 x 4.6 $\mathrm{mm}$, analytical column and the mobile phase was a mixture of $0.1 \%$ $(\mathrm{v} / \mathrm{v})$ formic acid in water to methanol at a ratio of 30:70 v/v. Injection volume was $10 \mu \mathrm{L}$. The flow rate was $0.50 \mathrm{ml} / \mathrm{min}$. Total analysis time of single injection was $2.0 \mathrm{~min}$. Column oven temperature and autosampler temperature was set to $30^{\circ} \mathrm{C}$ and $10^{\circ} \mathrm{C}$, respectively.

\section{Mass spectrometric conditions}

The LC eluent was split, and approximately $0.100 \mathrm{ml} / \mathrm{min}$ was introduced via electrospray ionisation using a Turbo Ion Spray interface set at $325{ }^{\circ} \mathrm{C}$ to generate positive ions $[\mathrm{M}+\mathrm{H}]+$. The Mass spectrometric parameters were optimised as shown in table no 1. 
Table 1: Mass spectrometric conditions

\begin{tabular}{|c|c|c|c|}
\hline Capillary voltage & & $3500 \mathrm{~V}$ & \\
\hline Nozzle voltage & & $1500 \mathrm{~V}$ & \\
\hline Delta $\operatorname{EMV}(+)$ & & 500 Positive & \\
\hline Gas flow & & $5 \mathrm{~L} / \mathrm{min}$ & \\
\hline Gas temperature & & $350^{\circ} \mathrm{C}$ & \\
\hline Nebulizer pressure & & 25 psi & \\
\hline Sheath gas temperature & & $300^{\circ} \mathrm{C}$ & \\
\hline Sheath gas flow & & $11 \mathrm{~L} / \mathrm{min}$ & \\
\hline Acquisition & & & \\
\hline Parameters & Sofosbuvir & & ISTD \\
\hline Transition & $428.35 / 279.26(\mathrm{~m} / \mathrm{z})$ & & $431.38 / 282.37(\mathrm{~m} / \mathrm{z})$ \\
\hline Polarity & Positive & & Positive \\
\hline MS1 resolution & Unit & & Unit \\
\hline MS2 resolution & Unit & & Unit \\
\hline Dwell time (millisec) & 200 & & 200 \\
\hline Fragmentor (V) & 100 & & 100 \\
\hline Collision energy (V) & 8 & & 10 \\
\hline
\end{tabular}

\section{Sample preparation method}

To $250 \mu \mathrm{l}$ of plasma, $50 \mu \mathrm{l}$ of ISTD $(1 \mu \mathrm{g} / \mathrm{ml})$ and $50 \mu \mathrm{l}$ of $0.1 \%$ formic acid was added and vortexed. The drug was extracted with $2.5 \mathrm{ml}$ of ethyl acetate, followed by centrifugation at $2000 \mathrm{rpm} / \mathrm{min}$ on a cooling centrifuge for $15 \mathrm{~min}$ at $4{ }^{\circ} \mathrm{C}$. The supernatant of $2 \mathrm{ml}$ was withdrawn and evaporated at $50^{\circ} \mathrm{C} 15$ psi of nitrogen until dryness at $\mathrm{LV}$ evaporator. The residue was reconstituted with $500 \mu \mathrm{l}$ of mobile phase, and respective samples were injected into the column.

\section{Validation [9-13]}

\section{Specificity}

A solution containing $4.063 \mathrm{ng} / \mathrm{ml}$ was injected onto the column under optimised chromatographic conditions to show the separation of sofosbuvir from impurities and plasma. The specificity of the method was checked for the interference from plasma.

\section{Linearity}

Spiked concentrations were plotted against peak area ratios of sofosbuvir to the internal standard and the best fit line was calculated. Wide range calibration was determined by solutions containing 4.063 to $8000.010 \mathrm{ng} / \mathrm{ml}$.

\section{Recovery studies}

The \% mean recoveries were determined by measuring the responses of the extracted plasma Quality control samples at HQC, MQC and LQC against un-extracted Quality control samples at HQC, $M Q C$ and LQC.

\section{Precision and accuracy}

The between-run (Inter-day) accuracy and precision evaluation were assessed by the repeated analysis of human $\mathrm{K}_{3}$ EDTA plasma samples containing different concentrations of sofosbuvir on separate occasions. A single run consisted of a calibration curve plus six replicates of the lower limit of quantitation, low, medium and high-quality control samples.

Within-run (Intraday) accuracy and precision evaluations were performed by analysing replicate concentrations of sofosbuvir in human $\mathrm{K}_{3}$ EDTA plasma. The run consisted of a calibration curve plus a total of 24 spiked samples, six replicates of each of the LLOQ, lower, medium and higher quality control samples.

\section{Matrix effect}

The matrix effect for the intended method was assessed by using chromatographically screened human plasma. Concentrations equivalent to LLOQ of Sofosbuvir were prepared with seven different plasma batches/lots. Samples were analysed along with one set of freshly spiked CC Standards prepared in the screened biological matrix.

\section{Ruggedness}

The ruggedness of the method was assessed by analysing a precision and accuracy batch using a different column, by the different analyst in another instrument.

\section{Stability studies}

\section{Short-term stock solution stability of sofosbuvir}

Solutions of sofosbuvir were prepared in methanol (Stability Samples) and were kept at room temperature for $6 \mathrm{~h} 30 \mathrm{~min}$. A freshly prepared solution of sofosbuvir (Comparison Samples) and stability samples were diluted at approximately the same analyte concentration and analysed in a single run; analyte responses were used to determine \% stability over time.

\section{Short-term stock solution stability of internal standard}

Solutions of internal standard (Sofosbuvir-d3) were prepared in methanol (Stability Samples) and were kept at room temperature for $6 \mathrm{~h} 30 \mathrm{~min}$. A freshly prepared solution of internal standard (Comparison Samples) and stability samples were diluted at approximately the same analyte concentration and analysed in a single run; Analyte responses were used to determine \% stability over time.

\section{Long-term stock solution stability of sofosbuvir}

Solutions of Sofosbuvir were prepared in methanol (Stability Samples) and were kept at refrigerator $\left(2-8{ }^{\circ} \mathrm{C}\right)$ for $10 \mathrm{D} 02 \mathrm{H}$. A freshly prepared solution of sofosbuvir (Comparison Samples) and stability samples were diluted at approximately the same analyte concentration and analysed in a single run.

\section{Long-term stock solution stability of internal standard}

Solutions of Internal standard were prepared in methanol (Stability Samples) and were kept at refrigerator $\left(2-8{ }^{\circ} \mathrm{C}\right)$ for $10 \mathrm{D} 02 \mathrm{H}$. A freshly prepared solution of internal standard (Comparison Samples) and stability samples were diluted at approximately the same analyte concentration and analysed in a single run.

\section{Freeze-thaw stability}

Samples were prepared at low and high-quality control levels, aliquoted and frozen at- $70{ }^{\circ} \mathrm{C}$. Some of the aliquots of quality control samples were subjected to five freeze-thaw cycles (stability samples). A calibration curve and quality control samples were freshly prepared (Comparison Samples) and processed with 6 replicates of stability samples and analysed in a single run.

\section{RESULTS AND DISCUSSION}

The chromatography observed during the course of validation was acceptable and representative chromatograms of standard blank, HQC, MQC, LQC and LLOQ are shown in fig. 1-3. 


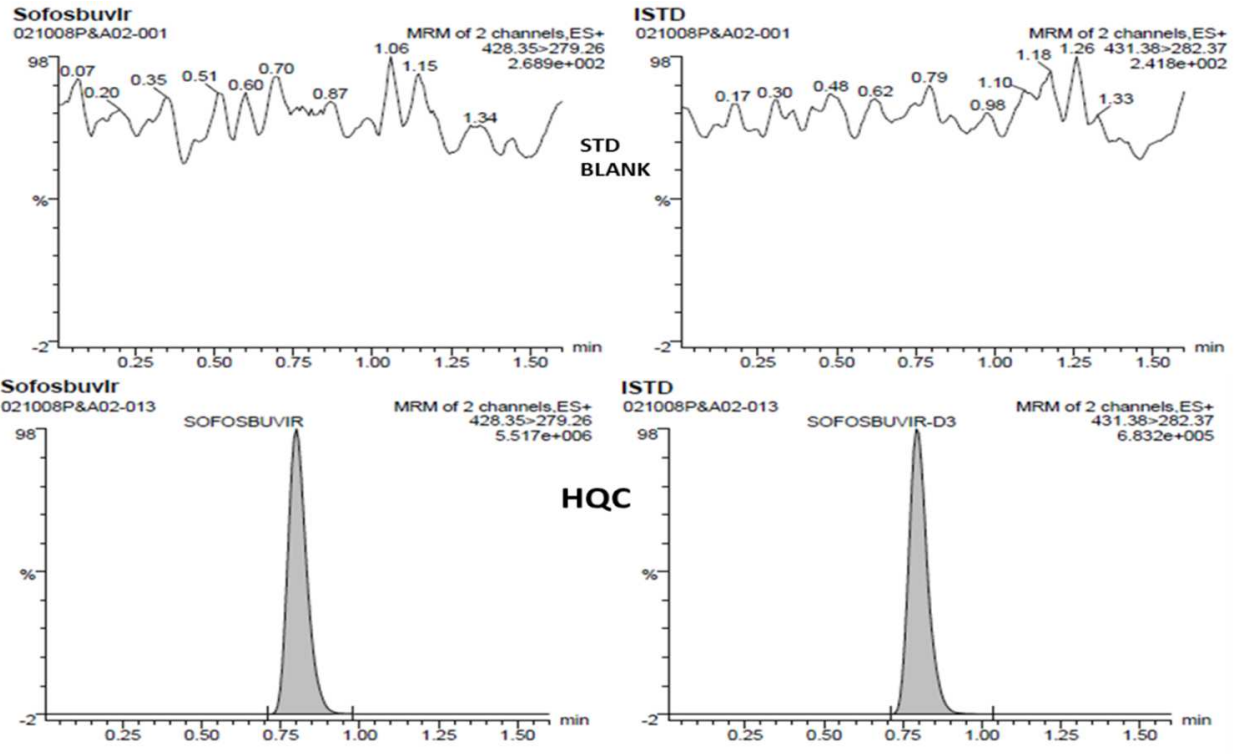

Fig. 1: Chromatograms of standard blank and HQC matrix

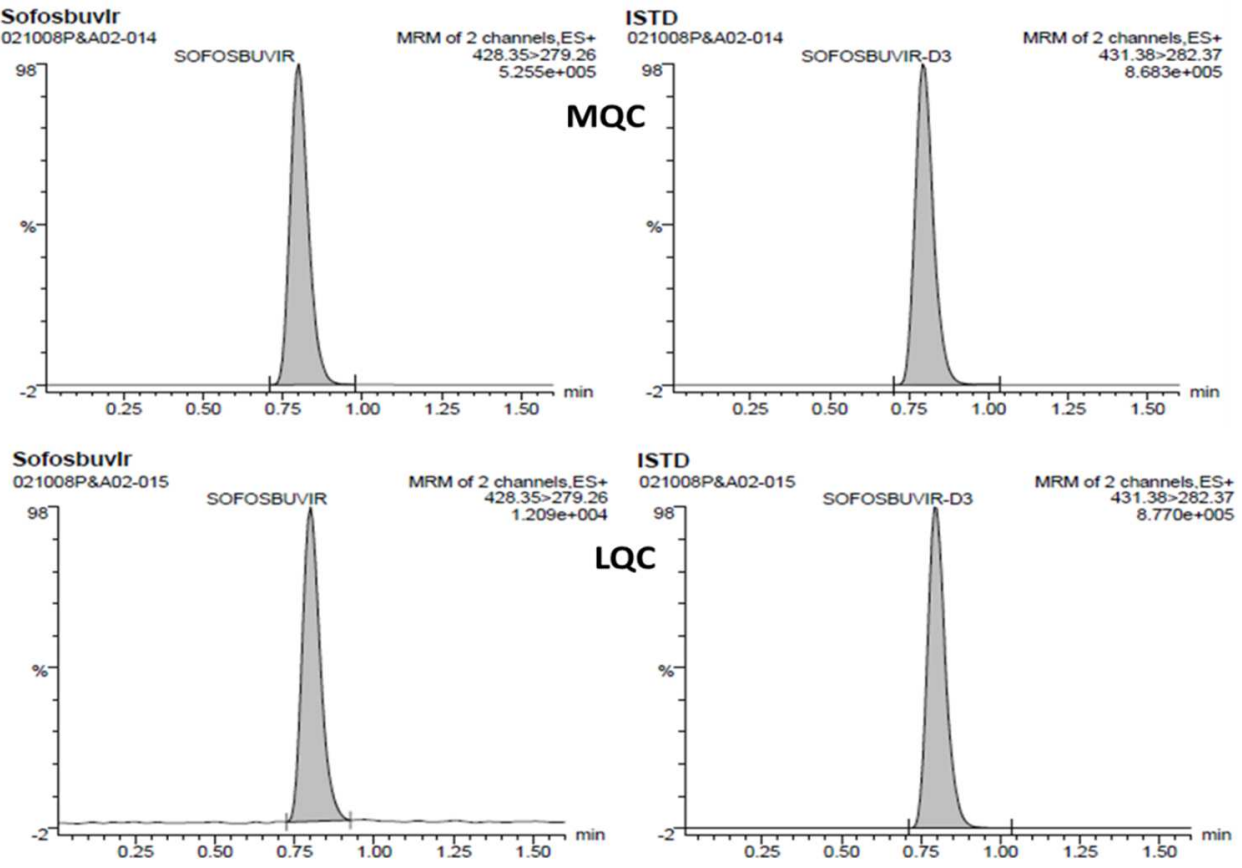

Fig. 2: Chromatograms of MQC and LQC
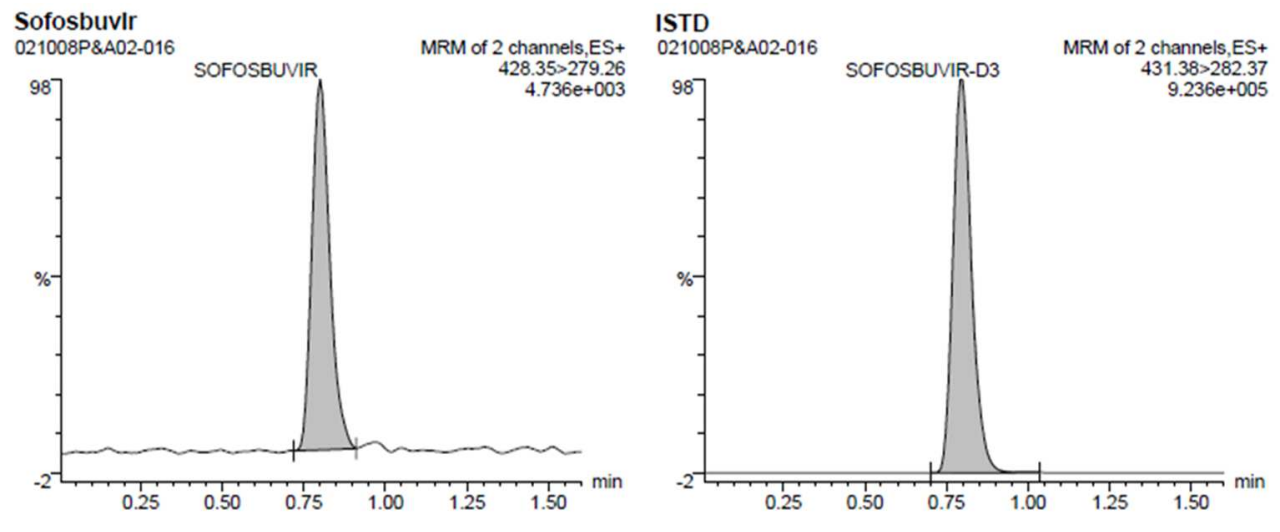

Fig. 3: Chromatograms of LLOQ 
The method developed was validated for specificity, accuracy and precision, linearity, ruggedness and stability as per FDA guidance [911]. The results of validating parameters are given below.

\section{Specificity}

Nine different lots of plasma were analysed to ensure that no endogenous interferences were present at the retention time of sofosbuvir and Sofosbuvir-d3. Nine LLOQ (4.063 ng/ml) level samples along with plasma blank from the respective plasma lots were prepared and analysed. (table 2). In all plasma blanks, the response at the retention time of sofosbuvir was less than $20 \%$ of LLOQ response and at the retention time of IS, the response was less than $5 \%$ of mean IS response in LLOQ. The typical chromatogram of plasma blank and the chromatogram of LLOQ was shown in (fig. 1).

Table 2: Results of specificity for sofosbuvir and sofosbuvir-d3 (ISTD)

\begin{tabular}{|c|c|c|c|c|c|c|c|c|}
\hline \multirow[t]{3}{*}{ S. No. } & \multicolumn{4}{|c|}{ Drug response } & \multicolumn{4}{|c|}{ ISTD response } \\
\hline & \multirow[t]{2}{*}{ STD BL } & \multicolumn{2}{|l|}{ LLOQ } & \multirow[t]{2}{*}{$\%$ Interference } & \multirow[t]{2}{*}{ STD BL } & \multicolumn{2}{|l|}{ LLOQ } & \multirow[t]{2}{*}{$\%$ Interference } \\
\hline & & Area & RT & & & Area & RT & \\
\hline 01 & 0 & 298 & 0.800 & NIL & 0 & 61776 & 0.800 & NIL \\
\hline 02 & 0 & 290 & 0.800 & NIL & 0 & 66613 & 0.800 & NIL \\
\hline 03 & 0 & 334 & 0.800 & NIL & 0 & 70621 & 0.800 & NIL \\
\hline 04 & 0 & 267 & 0.807 & NIL & 0 & 64807 & 0.800 & NIL \\
\hline 05 & 0 & 271 & 0.800 & NIL & 0 & 67694 & 0.800 & NIL \\
\hline 06 & 0 & 303 & 0.800 & NIL & 0 & 65249 & 0.800 & NIL \\
\hline 07 & 0 & 281 & 0.800 & NIL & 0 & 68774 & 0.800 & NIL \\
\hline 08 & 0 & 255 & 0.800 & NIL & 0 & 62927 & 0.800 & NIL \\
\hline 09 & 0 & 147 & 0.800 & NIL & 0 & 37012 & 0.800 & NIL \\
\hline 10 & 0 & 283 & 0.800 & NIL & 0 & 66641 & 0.800 & NIL \\
\hline
\end{tabular}

\section{Linearity}

The calibration curve (peak area ratio Vs Concentration) was linear over working range of 4.063 to $8000.010 \mathrm{ng} / \mathrm{ml}$ with ten point calibration used for quantification by linear regression, shown in (fig. 2). The regression equation for the analysis was
$\mathrm{Y}=0.0011227 \mathrm{x}-0.000164437$ with coefficient of correction $\left(\mathrm{r}^{2}\right)=$ 0.9985 .

\section{Recovery}

The \% mean recovery for sofosbuvir in LQC, MQC and HQC was $75.47 \%, 74.37 \%$ and $76.26 \%$ respectively (table 3 ).

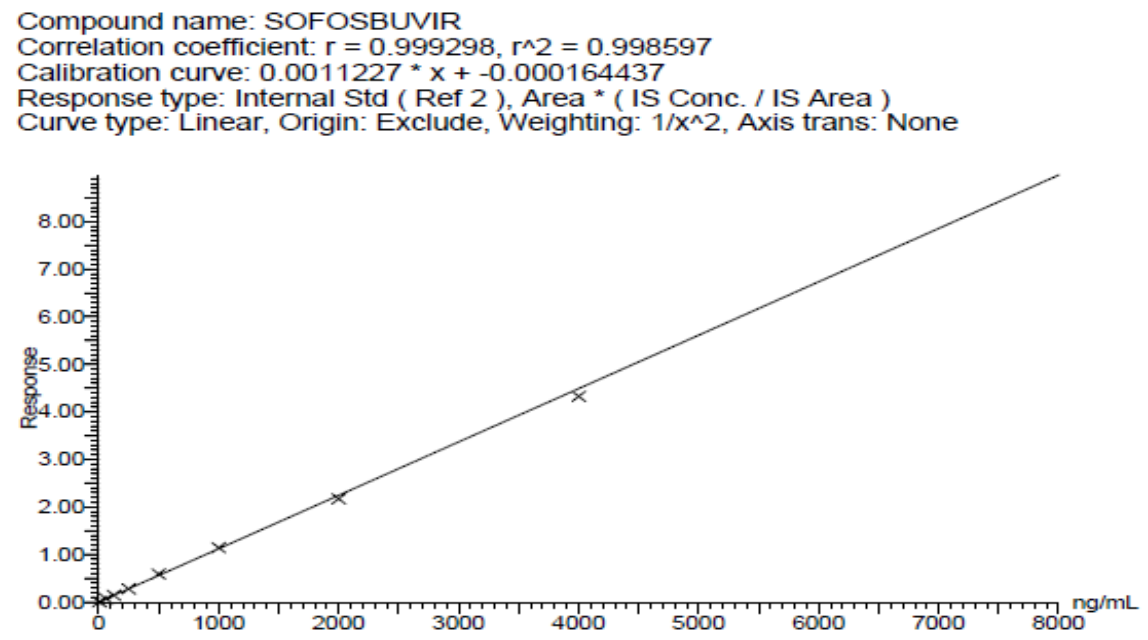

Fig. 3: Spiked concentrations $(4.063$ to $8000.010 \mathrm{ng} / \mathrm{ml})$ were plotted against calculated concentration Vs concentration with ten point calibration used for quantification by linear regression

Table 3: The \% mean recovery of sofosbuvir for LQC, MQC and HQC

\begin{tabular}{lllllll}
\hline S. No. & HQC & MQC & LQC & $\begin{array}{l}\text { Extracted area } \\
\text { ratio }\end{array}$ \\
\cline { 2 - 7 } & $\begin{array}{l}\text { Aqueous } \\
\text { area ratio }\end{array}$ & $\begin{array}{l}\text { Extracted area } \\
\text { ratio }\end{array}$ & $\begin{array}{l}\text { Aqueous area } \\
\text { ratio }\end{array}$ & $\begin{array}{l}\text { Extracted area } \\
\text { ratio }\end{array}$ & $\begin{array}{l}\text { ratio } \\
\text { area }\end{array}$ & 0.013 \\
01 & 13.466 & 8.226 & 0.981 & 0.598 & 0.022 & 0.013 \\
02 & 13.541 & 8.082 & 1.010 & 0.590 & 0.021 & 0.012 \\
03 & 13.318 & 7.995 & 0.995 & 0.571 & 0.021 & 0.013 \\
04 & 13.133 & 8.248 & 1.001 & 0.599 & 0.021 & 0.013 \\
05 & 12.997 & 7.994 & 0.985 & 0.600 & 0.0212 & 0.0128 \\
Mean & 13.2910 & 8.1090 & 0.9944 & 0.5916 & 0.00045 \\
SD & 0.22652 & 0.12243 & 0.01178 & 2.01218 & 3.49 \\
\% CV & 1.70 & 1.51 & 1.18 & & 75.47 & \\
\% Mean Recovery & 76.26 & & 74.37 & & & \\
\%Global Recovery & & & 75.36 & & & \\
\hline
\end{tabular}


Intraday (within run) and Inter-day (between run) precision and accuracy

The within-run coefficients of variation ranged between $1.06 \%$ and $5.06 \%$ for sofosbuvir. The within-run percentages of nominal concentrations ranged between $97.21 \%$ and $105.93 \%$ for sofosbuvir. Results are presented in table 4.

The between-run coefficients of variation ranged between $2.04 \%$ and $5.48 \%$ for sofosbuvir. The between-run percentages of nominal concentrations ranged between $98.34 \%$ and $100.58 \%$ for sofosbuvir. Results are presented in table 4.

\section{Matrix effect}

The \% accuracy of LLOQ samples prepared with the different biological matrix lots were found within the range of 89.49 to $97.49 \%$ which were found within the range of $80.00-120.00 \%$ for the seven different plasma lots. \% CV for LLOQ samples was observed as $2.87 \%$ which are within $20.00 \%$ of the acceptance criteria. Results are presented in table 5 .

Table 4: Intraday and interday precision and accuracy

\begin{tabular}{|c|c|c|c|c|}
\hline QC ID & HQC & MQC & LQC & LLOQ QC \\
\hline Concentration (ng/ml) & 7252.503 & 522.180 & 11.488 & 4.136 \\
\hline \multicolumn{5}{|c|}{ Within Batch Precision and Accuracy } \\
\hline \multirow[t]{6}{*}{ PandA I } & \multicolumn{4}{|c|}{ Calculated Concentration (ng/ml) } \\
\hline & 6910.342 & 511.080 & 11.630 & 4.290 \\
\hline & 7009.484 & 518.984 & 10.484 & 3.998 \\
\hline & 7189.506 & 514.176 & 11.501 & 4.116 \\
\hline & 7156.740 & 511.840 & 11.892 & 4.132 \\
\hline & 6984.985 & 504.031 & 11.887 & 4.477 \\
\hline Mean & 7050.211 & 512.0222 & 11.4788 & 4.2026 \\
\hline SD & 118.5622 & 5.42876 & 0.58102 & 0.18526 \\
\hline$\% \mathrm{CV}$ & 1.68 & 1.06 & 5.06 & 4.41 \\
\hline$\%$ Mean Accuracy & 97.21 & 98.05 & 99.92 & 101.61 \\
\hline \multirow[t]{5}{*}{ PandA II } & 7234.610 & 533.688 & 12.086 & 4.263 \\
\hline & 7192.185 & 531.929 & 12.605 & 4.266 \\
\hline & 7272.508 & 523.890 & 12.009 & 4.246 \\
\hline & 7351.433 & 522.452 & 11.705 & 4.070 \\
\hline & 7380.960 & 535.319 & 12.440 & 4.172 \\
\hline Mean & 7286.339 & 529.4556 & 12.1690 & 4.2034 \\
\hline SD & 78.93435 & 5.88296 & 0.35753 & 0.08377 \\
\hline$\% \mathrm{CV}$ & 1.08 & 1.11 & 2.94 & 1.99 \\
\hline$\%$ & 100.47 & 101.39 & 105.93 & 101.63 \\
\hline \multicolumn{5}{|l|}{ Mean Accuracy } \\
\hline \multirow[t]{5}{*}{ PandA III } & 7161.887 & 520.892 & 11.414 & 4.123 \\
\hline & 7036.505 & 514.024 & 11.006 & 4.395 \\
\hline & 6960.208 & 497.103 & 10.554 & 4.354 \\
\hline & 7181.121 & 521.290 & 11.095 & 4.168 \\
\hline & 6960.064 & 522.273 & 11.006 & 4.342 \\
\hline Mean & 7059.957 & 515.1164 & 11.0150 & 4.2764 \\
\hline SD & 106.7109 & 10.58730 & 0.30752 & 0.12214 \\
\hline$\% \mathrm{CV}$ & 1.51 & 2.06 & 2.79 & 2.86 \\
\hline \% Mean Accuracy & 97.35 & 98.65 & 95.88 & 103.39 \\
\hline \multicolumn{5}{|c|}{ Between Batch Precision and Accuracy } \\
\hline Mean & 7132.169 & 518.8647 & 11.5543 & 4.2275 \\
\hline SD & 147.64818 & 10.58931 & 0.63313 & 0.13174 \\
\hline$\% \mathrm{CV}$ & 2.07 & 2.04 & 5.48 & 3.12 \\
\hline$\%$ Mean Accuracy & 98.34 & 99.37 & 100.58 & 102.21 \\
\hline
\end{tabular}

Table 5: Results of matrix effect

\begin{tabular}{lll}
\hline LLOQ nominal concen (4.063ng/ml) & \% accuracy \\
\hline S. No. & Calculated LLOQ concn (ng/ml) & 96.9 \\
\hline 1 & 3.937 & 93.73 \\
2 & 3.808 & 94.09 \\
3 & 3.823 & 97.49 \\
4 & 3.961 & 89.49 \\
5 & 3.636 & 95.17 \\
6 & 3.867 & 92.69 \\
7 & 3.766 & 94.223 \\
& $\%$ Mean accuracy & 2.7003 \\
\end{tabular}

\section{Ruggedness}

The coefficients of variation ranged between $0.35 \%$ and $3.09 \%$ for sofosbuvir. The percentages of nominal concentrations ranged between $93.2 \%$ and $99.29 \%$ for sofosbuvir. Results are presented in table 6.

\section{Stability studies}

\section{Short-term stock solution stability of sofosbuvir and internal} standard

Sofosbuvir and internal standard were found to be stable in methanol for $6 \mathrm{~h} 30 \mathrm{~min}$ at room temperature with a \% stability of $97.25 \%$ and $97.0 \%$ respectively. Results are presented in table 7.
Long-term stock solution stability of sofosbuvir and internal standard

Sofosbuvir and internal standard were found to be stable in methanol $10 \mathrm{D} 02 \mathrm{H}$ at refrigerator $\left(2-8{ }^{\circ} \mathrm{C}\right)$ with a \% stability of $98.81 \%$ and $107.96 \%$ respectively. Results are presented in table 8 .

\section{Freeze-thaw stability}

Sofosbuvir is found to be stable in human $\mathrm{K}_{3}$ EDTA plasma after five freeze-thaw cycles at- $70{ }^{\circ} \mathrm{C}$ with coefficients of variation of $3.27 \%$ (LQC) and 3.86\% (HQC) for sofosbuvir, and the percentages of nominal concentrations for sofosbuvir were found to be $103.17 \%$ (LQC) and 101.23\% (HQC). Results are presented in table 9. 
Table 6: Results of ruggedness with different column

\begin{tabular}{llll}
\hline QC ID & HQC & MQC & LQC \\
\hline Conc.(ng/ml) & 7252.503 & 522.180 & 11.488 \\
PandA ID & Calculated concentration (ng/ml) & \\
Different & Acquisition batch ID: 031008PandADC01 & \\
Column & 6980.672 & 523.650 & 11.419 \\
& 7005.431 & 518.262 & 11.463 \\
& 7243.518 & 521.038 & 11.403 \\
Mean & 7100.206 & 527.007 & 11.307 \\
SD & 7312.115 & 516.714 & 11.443 \\
\% CV & 7128.3884 & 521.3342 & 3.725 \\
Mean Accuracy & 145.55342 & 4.13570 & 3.861 \\
& 2.04 & 0.79 & 3.790 \\
& 98.29 & 99.84 & 0.06040 \\
\end{tabular}

Table 7: Short-term stock solution stability of drug and ISTD

\begin{tabular}{llll}
\hline S. NO. & Drug & & ISTD \\
\cline { 2 - 4 } & $\begin{array}{l}\text { Nominal Conc }(\mathbf{n g} / \mathbf{m l}) \\
\mathbf{3 9 6 6 7 5 . 1 9}\end{array}$ & $\mathbf{4 0 0 0 0 0 . 4}$ & $\begin{array}{l}\text { Nominal Conc }(\boldsymbol{\mu g} / \mathbf{m l}) \\
\mathbf{4 . 0 3 4}\end{array}$ \\
\cline { 2 - 4 } & $\begin{array}{l}\text { Area ratio } \\
\text { comparison samples }\end{array}$ & Stability samples & $\begin{array}{l}\text { Area ratio } \\
\text { Comparison samples }\end{array}$ \\
\hline 01 & 9.134 & 9.076 & 0.116 \\
02 & 9.181 & 8.829 & 0.117 \\
03 & 9.147 & 9.090 & 0.115 \\
04 & 9.082 & 8.973 & 0.117 \\
05 & 9.231 & 8.946 & 0.114 \\
06 & 9.197 & 8.996 & 0.117 \\
Mean & 9.1620 & 8.9850 & 0.1160 \\
SD & 0.05245 & 0.09532 & 0.00126 \\
$\%$ CV & 0.57 & 1.06 & 1.09 \\
$\%$ Mean Stability & 97.25 & & 0.117 \\
& & & 0.113 \\
\end{tabular}

Table 8: Long-term stock solution stability of drug and internal standard

\begin{tabular}{llll}
\hline S. No. & DRUG & & ISTD \\
\cline { 2 - 4 } & $\begin{array}{l}\text { Nominal Conc (ng/ml) } \\
\mathbf{4 0 0 0 0 0 . 4 8 0}\end{array}$ & $\mathbf{3 9 8 1 8 6 . 2 4 0}$ & $\begin{array}{l}\text { Nominal Conc ( } \mathbf{\mu g} / \mathbf{m l}) \\
\mathbf{4 . 2 1 4}\end{array}$ \\
\cline { 2 - 4 } & Area ratio & & Area ratio \\
\cline { 2 - 3 } & Comparison samples & Stability samples & Comparison samples \\
\hline 01 & 9.219 & 9.049 & 0.108 \\
02 & 9.116 & 9.111 & 0.107 \\
03 & 9.228 & 9.026 & 0.108 \\
04 & 8.918 & 9.141 & 0.112 \\
05 & 9.208 & 9.073 & 0.111 \\
06 & 9.138 & 9.022 & 0.113 \\
Mean & 9.1378 & 9.0703 & 0.1098 \\
SD & 0.11700 & 0.04777 & 0.110 \\
\% CV & 1.28 & 0.53 & 0.115 \\
\% Mean Stability & 98.81 & & 0.119 \\
& & & 0.119 \\
\end{tabular}

Table 9: Freeze-thaw stability at-70 ${ }^{\circ} \mathrm{C}$

\begin{tabular}{llll}
\hline S. No. & HQC & & LQC \\
\cline { 2 - 4 } & Nominal Conc $(\mathbf{n g} / \mathbf{m l})$ & & Nominal Conc (ng/ml) \\
& $\mathbf{7 2 5 2 . 5 0 3}$ & $\mathbf{1 1 . 4 8 8}$ & Calculated Conc (ng/ml) \\
\cline { 2 - 4 } & Calculated Conc $(\mathbf{n g} / \mathbf{m l})$ & 100.04 & 11.571 \\
\hline 1 & 7255.363 & 96.32 & 11.547 \\
2 & 6985.35 & 96.76 & 12.168 \\
\hline
\end{tabular}

\section{CONCLUSION}

Chromatographic separation was performed on Gemini $5 \mu$ C18, 50 x 4.6 $\mathrm{mm}$, analytical column and the mobile phase was a mixture of $0.1 \%$ $(\mathrm{v} / \mathrm{v})$ formic acid in water to methanol at a ratio of 30:70 v/v. The drug was extracted from the sample with $2.5 \mathrm{ml}$ of ethyl acetate. The specificity of the method was checked for the interference from plasma. Wide range calibration was determined by solutions containing 4.063 to
$8000.010 \mathrm{ng} / \mathrm{ml}$. The \% mean recovery for sofosbuvir in LQC, MQC and HQC was $75.47 \%, 74.37 \%$ and $76.26 \%$ respectively. The within-run coefficients of variation ranged between $1.06 \%$ and $5.06 \%$ for sofosbuvir. The between-run coefficients of variation ranged between $2.04 \%$ and $5.48 \%$ for sofosbuvir the \% accuracy of LLOQ samples prepared with the different biological matrix lots were found within the range of 89.49 to $97.49 \%$. Stability test were performed to assess the long term and short term stability of sofosbuvir sample solutions, 
internal standard solutions. The developed method was validated for the quantitative determination of sofosbuvir from plasma was simple, rapid, specific, sensitive, accurate and precise. Hence, the method is quite suitable to detect the drug from plasma samples of human volunteers.

\section{ACKNOWLEDGEMENT}

I am also grateful to my scholars and my friends for their kind help from time to time at each and every step of my project work.

\section{CONFLICT OF INTERESTS}

\section{Declared none}

\section{REFERENCES}

1. https://pubchem.ncbi.nlm.nih.gov/compound/45375808. Last accessed on 12 Jun 2016]

2. Hoofnagle J, Di Bisceglie A. The treatment of chronic viral hepatitis. N Eng J Med 1997;336:347-56.

3. Ravikumar V, Subramanyam CVS, Veerabhadram G. Estimation and validation of sofosbuvir in bulk and tablet dosage form by RP-HPLC. Int J Pharm 2016;6:121-7.

4. Mohan Vikas P, Satyanarayana T, Vinod Kumar E, Mounika E, Sri Latha M, Anusha R, et al. Development and validation of new RP-HPLC method for the determination of sofosbuvir in pure form. World J Pharm Pharm Sci 2016;5:775-81.

5. Rezk MR, Basalious EB, Karim IA. Development of a sensitive UPLC-ESI-MS/MS method for quantification of sofosbuvir and its metabolite, GS-331007, in human plasma: application to a bioequivalence study. J Pharm Biomed Anal 2015;114:97-104.
6. Rezk MR, Basalious EB, Amin ME. Novel and sensitive UPLCMS/MS method for quantification of sofobuvir in human plasma: application to a bioequivalence study. Biomed Chromatogr 2016;30:1354-62.

7. Shi X, Zhu D, Lou J, Gan D. Evaluation of a rapid method for the simultaneous quantification of ribavirin, sofobuvir and its metabolites in rat plasma by UPLC-MS/MS method. J Chromatogr B: Anal Technol Biomed Life Sci 2015;1002:353-7.

8. Analytical procedures and methods validation for drugs and biologics guidance for industry. U. S. Department of Health and Human Services, Food and Drug Administration Center for Drug Evaluation and Research (CDER), Center for Biologics Evaluation and Research (CBER); 2015.

9. Sindhusri M, Swetha T, Ramadevi A, Ashok Kumar A. A novel rapid rp-hplc method development and validation for the quantitative estimation of balofloxacin in tablets. Int J Pharm Pharm Sci 2014;7:319-22.

10. Raveendra Babu G, Lakshmana Rao A, Venkateswara Rao J. A rapid RP-HPLC method development and validation for the quantitative estimation ribavirin in tablets. Int J Pharm Pharm Sci 2014;7:60-3.

11. Srinidhi M, Mushabbar Basha MD, V Raj Kumar, Rajendra Kumar J. Stability indicating RP-HPLC method development and validation for the estimation of sumatriptan in bulk and pharmaceutical dosage form. J Appl Pharm Sci 2016;6:20-5.

\section{How to cite this article}

- Darshan Bhatt, B Rajkamal. A UPLC-MS/MS method development and validation for the estimation of sofosbuvir from human plasma. Int J Appl Pharm 2017;9(1):30-36. 